DOI: 10.38136/jgon.874135

\title{
Elektif ve Acil Serklaj Uygulamalarının Perinatal Sonuçlar Açısından Analizi
}

\section{Analysis of Elective and Emergency Cerclage Practice in Terms of Perinatal Results}

\author{
Burak AKSELIM \\ Seyhan SÖNMEZ \\ Süleyman Serkan KARAȘiN
}

(1) Orcid ID:0000-0003-1558-0899

(1) Orcid ID:0000-0002-0216-7491

(1) Orcid ID:0000-0002-4837-5114

\section{${ }^{1}$ Bursa Yüksek Ihtisas Eğitim ve Araștırma Hastanesi, Kadın Hastalıkları ve Doğum Kliniği, Bursa, Türkiye}

\section{ÖZ}

Amaç: Sevk alan üçüncü basamak merkezimizde yapılan elektif ve acil servikal serklaj sonuçlarını incelemeyi ve etkinliklerini değerlendirmeyi amaçladık

Gereçler ve Yöntem: Bursa Yüksek İhtisas Eğitim ve Araştırma Hastanesi'nde Ocak 2016 ile Ocak 2020 arasında servikal yetmezlik tanısılla servikal serklaj yapılan toplam 56 hastanın sonuçları retrospektif olarak incelenmiştir. Transvajinal olarak Mc-Donald tipi serklaj uygulanan hastalar çalışmaya dahil edilmiştir. Çoğul gebeliği olan, abdominal serklaj uygulanan ve doğum sonuçlarına ulaşılamayan hastalar çalışma dışı bırakımıştı. Serklaj yapııma endikasyonuna göre hastalar; elektif serklaj (öykü endikasyonlu) ve acil serklaj (fizik muayene ve ultrasonografi endikasyonlu) olmak üzere iki grupta incelenmiştir.

Bulgular: Serklaj işleminin yapıılığı gebelik haftası elektif ve acil grupları için sırasıyla $20.8 \pm 0.7$ ve $13.9 \pm 0.1$ hafta olarak saptandı. Elektif serklaj yapılan grupta serklaj işlemi ile doğum arasında geçen süre ile doğumun gerçekleştiği hafta belirgin olarak daha fazlaydı ( $151.1 \pm 6.5$ gün / $35.2 \pm 0.9$ hafta vs $23.7 \pm 18.5$

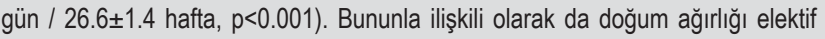
serklaj yapılan grupta acil serklaj yapılan gruptan anlamlı olarak daha fazlaydı (2913.7 \pm 129 gr vs $1611.4 \pm 232.2$ gr, $p<0.001)$. Yenidoğan yoğun bakım gereksinimi ise elektif serklaj grubunda daha azdı ( $p=0.011)$. Doğum şekli ve abortus oranı açısından ise her iki grup arasında istatiksel anlamlı fark yoktu ( $p>0.05)$.

Sonuç: Ağrısız servikal açıkıı ile başvuran ya da ultrasonografide belirgin kısa servikse sahip hastalarda yapılan acil serklaj ile her ne kadar gebelik süresi uzatılııp kötü perinatal sonuçlar azaltılsa bile bu etkiler elektif serklaj kadar değildir. Elektif serklaja kıyasla acil serklaj etkinliğini belirlemek için acil serklaj uygulanan hastaların daha iyi randomize edildiği daha fazla hasta sayısı ile yapılacak prospektif çalışmalara intiyaç vardır.

Anahtar kelimeler: Servikal serklaj,servikal yetmezlik,preterm doğum

\section{ABSTRACT}

Aim: We aimed to examine the elective and emergency cervical cerclage results performed in our referral tertiary care center and evaluate their effectiveness.

Materials and Methods: The results of 56 patients who underwent cervical cerclage with the diagnosis of cervical insufficiency in Bursa Yüksek Ihtisas Training and Research Hospital between January 2016 and January 2020 were retrospectively analyzed. Patients who underwent Mc-Donald type transvaginal cerclage were included in the study. Patients with multiple pregnancies, abdominal cerclage, and deliver results that could not be reached were excluded from the study. According to the cerclage indication, patients were examined in two groups as elective cerclage (with history indication) and emergency cerclage (with physical examination and ultrasonography indication).

Results: The gestational week when cerclage was performed was determined as $20.8 \pm 0.7$ and $13.9 \pm 0.1$ weeks for elective and emergency groups, respectively. In the elective cerclage group, the time between cerclage procedure and delivery and the week of delivery was significantly higher $(151.1 \pm 6.5$ days / $35.2 \pm 0.9$ weeks vs. $23.7 \pm 18.5$ days / $26.6 \pm 1.4$ weeks, $p<0.001$ ). In relation to this, birth weight was significantly higher in the elective cerclage group than in the emergency cerclage group $(2913.7 \pm 129 \mathrm{gr}$ vs. $1611.4 \pm 232.2 \mathrm{~g}$, $p<0.001)$. Neonatal intensive care requirement was less in the elective cerclage group $(p=0.011)$. There was no statistically significant difference between the two groups in terms of delivery method and abortion rate ( $p>0.05)$.

Conclusion: Although the gestation period is more prolonged and poor perinatal outcomes are lower with emergency cerclage performed in patients presenting with painless cervical opening or a prominent short cervix on ultrasonography, these effects are not as much elective cerclage. There is a need for prospective studies to determine the efficacy of emergency cerclage compared to elective cerclage, in which patients with emergency cerclage are better randomized and with a larger number of patients.

Keywords: Cervical cerclage,cervical insufficiency,preterm birth 
Servikal yetmezlik, preterm doğumların önemli nedenlerinden biridir ve tüm gebeliklerin $\% 0.1$ ile $\% 1$ 'ini etkiler. Aynı zamanda gebeliğin ikinci üç ayındaki tekrar eden düşüklerin de \%8'inden sorumludur (1, 2). Servikal yetmezlik, uterin serviksin gebeliğin ikinci üç ayında klinik kasılmalar, doğum eylemi ya da her ikisi olmamasına rağmen gebeliğin devamını sağlayamaması olarak tanımlanmıştır. Tanısı genellikle ağrısız ikinci üç ay düşük ya da erken doğum yapan kadınlarda geriye dönük olarak konur (3). Konjenital uterin anomaliler, tekrar eden dilatasyon ve küretaja bağlı cerrahi travma, servikal konizasyon ve trakelektomi, diethylstilbestrol maruziyeti, Ehlers-Danlos Sendromu ve benzeri bağ doku hastalıkları servikal yetmezlik etyolojisi ile ilişkilendirilen durumlardan bazılarıdır $(4,5)$.

Servikal yetmezlik tanısı, objektif bulguları ile tanı kriterlerinin net olmaması nedeni ile zor konulmakta olup farklıık gözlenebilmektedir. Bunun engellenmesi için bazı tanımlamalar kullanılmıştır. Servikal yetmezlik tedavisinde en yaygın kullanılan cerrahi girişim serklaj uygulamalarıdır. Servikal serklaj preterm doğuma bağlı kötü perinatal sonuçları önlemek amacıyla çeşitli sütür materyalleri kullanılarak, serviksin kaybolan gerilim direncini arttırmak amacıyla uygulanan mekanik cerrahi müdahalelerdir.

Servikal yetmezlikte serklaj endikasyonları sıkıkla üç grupta toplanmıştır. Doğum ağrısı ya da dekolmanın olmadığı ağrısız servikal dilatasyona bağı bir veya daha fazla ikinci trimester gebelik kaybı ve geçirilmiş serklaj öyküsünü "öykü endikasyonlu serklaj", gebeliğin ikinci üç ayında dijital ya da spekulum muayenesinde ağrısız servikal dilatasyonun olmasını "fizik muayene endikasyonlu serklaj", mevcut gebeliğinin 24. Haftasından önce serviks uzunluğunun 25 mm den kısa olması ve daha öncesinden 34 hafta altı doğum öyküsünün olması "ultrasonografi endikasyonlu serklaj” olarak tanımlamıştır (3, 6-9). Öykü endikasyonlu serklaj uygulamaları "profilaktik/elektif serklaj" olarak tanımlanırken, fizik muayene ve ultrasonografi endikasyonlu serklaj uygulamaları ise "acil serklaj" olarak tanımlanmıştır (3).

Bu çalışmada, sevk alan üçüncü basamak merkezimizde yapılan elektif ve acil servikal serklaj sonuçlarını incelemeyi ve etkinliklerini değerlendirmeyi amaçladık.

\section{GEREÇ VE YÖNTEMLER}

Bu çalışma kapsamında Bursa Yüksek Ihtisas Eğitim ve Araştırma Hastanesi'nde Ocak 2016 ile Ocak 2020 arasında servikal yetmezlik tanısıyla servikal serklaj yapılan toplam 56 hastanın sonuçları retrospektif olarak incelenmiştir. Serklaj yapılma endikasyonuna göre hastalar; elektif serklaj ve acil serklaj olmak üzere iki alt gruba ayrılmıştır. Daha önceden servikal yetmezlik öyküsü olan ve prenatal tarama testi yapılıp gebeliklerinin ilk üç ayında öykü endikasyonlu servikal serklaj yapılan hastalar elektif serklaj grubuna ( $n=35$ ); mevcut gebeliğinin ikinci üç ayında ağrısız servikal açıklığı olan ya da preterm doğum öyküsü (34 hafta altı) ve ultrasonografide kısa serviks (25 mm altı) olması üzerine fizik muayene ve ultrasonografi endikasyonlu serklaj yapılan hastalar acil serklaj grubuna dahil edilmiştir $(n=21)$. Aktif uterin kontraksiyon, aktif vajinal kanama, klinik koryoamnionit, membran rüptürü olan veya yaşamla bağdaşmayan fetal anomalili fetusa sahip hastalara serklaj yapılmamıştır. Çoğul gebeliği olan, abdominal serklaj uygulanan ve doğum sonuçlarına ulaşılamayan hastalar çalışma dışı bırakılmıştır. Tüm hastalara Mc-Donald tipi transvajinal serklaj uygulanmıştır. Spinal ya da genel anestezi altında povidone iodine ile yapılan sterilizasyon sonrası mersilen sütür kullanarak internal osa mümkün olduğunca yakın olacak şekilde servikal sütürasyon uygulanmıştır. Prolabe membran varlığında foley katater kullanılarak redüksiyon yapıımıştır. İşlem sonrası kısa süreli indometazin ve progesterone kullanılmışır. Hastaların takiplerinde aktif uterin kontraksiyon, amnion sıvı drenajı veya korioamnionit varlığında hemen, yoksa 36-37. gebelik haftasında serklaj ipi alınmıştır.

\section{İstatistiksel metod}

Uygun istatistiksel analizler için Windows tabanlı SPSS 24.0 istatistiksel analiz programı (SPSS Inc., ABD) kullanıldı. Verilerin normal dağı̆ım gösterip göstermediklerini belirlemek için değişkenler görsel (histogramlar, olasılık grafikleri) ve analitik yöntemlerle (Shapiro-Wilk ve Kolmogorov Smirnov testi) incelenmiştir. Değişkenler ortalama \pm standart sapma $(X \pm S S)$, gruplar arası ortalama fark, \% 95 güven aralığı (\% $95 \mathrm{GA}$ ), medyan (minimum-maksimum (min-maks)), frekans (n) ve yüzde (\%) olarak tanımlandı. Elektif ve acil serklaj gruplarını karşılaştırdığımız iki gruplu analizde normal dağılmış ve dağılmamış değişkenleri karşılaştırmak için sırasıyla Student $t$ testi ve Mann-Whitney U testi kullanıldı. Tip 1 hata düzeyinin \%5'in altında olduğu durumlar $(p<0.05)$ istatistiksel olarak anlamlı kabul edildi.

\section{BULGULAR}

Çalışma periyodu boyunca hastanemiz kadın hastalıkları ve doğum kliniğinde 84 hastaya serklaj işlemi uygulanmıştır. Serklaj sonrası gebelik sonuçlarına ulaşılamaması nedeniyle 15 hasta, ikiz gebelik nedeni ile 2 hasta ve abdominal serklaj uygulanan 1 hasta çalışma dışı bırakılmış olup, servikal yetmezlik nedeniyle servikal serklaj yapılan tekil gebeliğe sahip toplam 56 hastanın 
734 AKSELIM B.

sonuçları analiz edilmiştir. Bu hastaların 35'ine elektif serklaj, 21 'ine ise acil serklaj yapılmış ve sonuçları iki ayrı grupta değerlendirilmiştr. Benzer yaş dağılımına sahip iki grup hastadan elektif serklaj yapılan hastaların önceki gebelik ve doğum sayısı acil serklaj yapılan hastalardan anlamlı olarak daha fazlaydı. Serklaj işleminin yapıldığı gebelik haftası elektif ve acil grupları için sırasıyla $20.8 \pm 0.7$ ve $13.9 \pm 0.1(p<0.05)$ hafta olarak tespit edilmiş ve her iki gruba ait temel maternal karekteristikler Tablo 1 de belirtilmiştir. Tablo 2 de ise her iki gruba ait gebelik sonuçları özetlenmiş̧ir. Elektif serklaj yapılan grupta serklaj işlemi ile doğum arasında geçen süre ile doğumun gerçekleştiği hafta belirgin olarak daha fazlaydı (151.1 \pm 6.5 gün / 35.2 \pm 0.9 hafta vs $23.7 \pm 18.5$ gün / 26.6 \pm 1.4 hafta ) Bununla ilişkili olarak da doğum ağırlığı elektif serklaj yapılan grupta acil serklaj yapılan gruptan anlamlı olarak daha fazla ( $2913.7 \pm 129 \mathrm{gr}$ vs $1611.4 \pm 232.2 \mathrm{gr}$ ) olup, yenidoğan yoğun bakım intiyacı ise daha azdı. Doğum şekli ve abortus oranı açısından ise her iki grup arasında istatiksel anlamlı fark yoktu.

Tablo 1. Hastaların demografik ve obstetrik özellikleri

\begin{tabular}{|l|l|l|l|}
\hline & $\begin{array}{l}\text { Elektif serklaj } \\
(\mathrm{n}=35)\end{array}$ & $\begin{array}{l}\text { Acil serklaj } \\
(\mathrm{n}=21)\end{array}$ & $\mathrm{p}$ - değeri \\
\hline Yaş & $28.9 \pm 1.09$ & $28.9 \pm 1.55$ & 0.984 \\
\hline Gebelik sayıs1 & $3(2-12)$ & $1.5(1-6)$ & $<0.001$ \\
\hline Doğum sayıs1 & $1(0-3)$ & $0(0-2)$ & 0.005 \\
\hline $\begin{array}{l}\text { Geçirilmiş serklaj } \\
\text { öyküsü }\end{array}$ & $9(16,4)$ & $0(0-0)$ & 0.010 \\
\hline Serklaj haftas1 & $13.9 \pm 0.1$ & $20.8 \pm 0.7$ & $<0.001$ \\
\hline
\end{tabular}

Veriler ortalama \pm standart sapma, ortanca (minimum-maksimum) ve sayı(\%) olarak gösterilmiştir. $P<0.05$ istatistiksel olarak anlamlı kabul edilmiştir

Tablo 2. Hastaların perinatal ve yenidoğan sonuçları

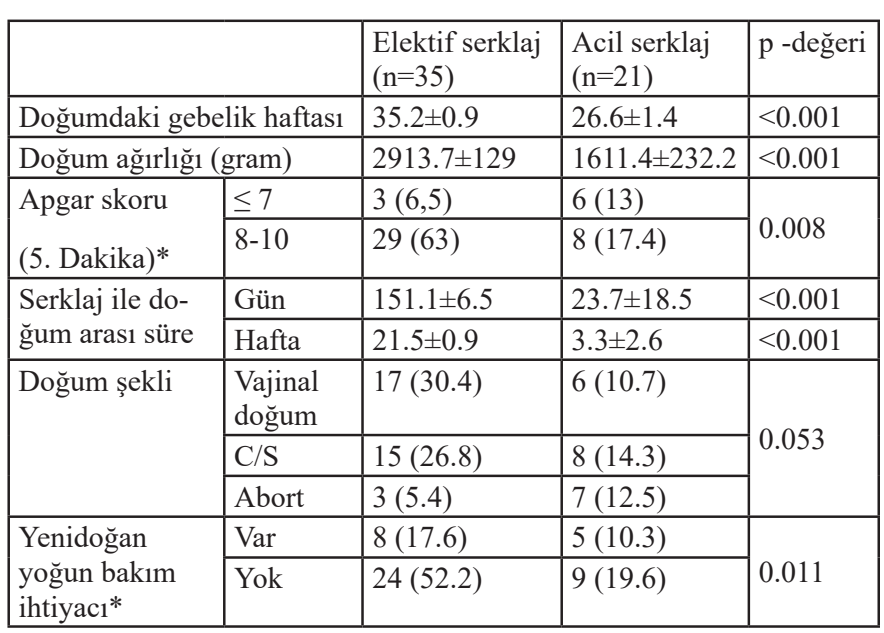

*Sadece canlı doğumlar

Veriler ortalama \pm standart sapma, ortanca (minimum-maksimum) ve sayı(\%) olarak gösterilmiştir. $\mathrm{P}<0.05$ istatistiksel olarak anlamlı kabul edilmiştir.

\section{TARTIŞMA}

Preterm doğum tüm dünyada en önemli obstetrik sorunlardan biridir ve perinatal ölümlerin \%70'inden sorumludur (10). Servikal yetmezlik ise önemli bir preterm doğum ve ikinci üç ay düşük nedenidir. Tarihsel olarak servikal yetmezlik tedavisinde yatak ıstırahati, fiziksel aktivite kısıllaması ya da pesser uygulaması gibi cerrahi dışı yöntemler denenmiş ve etkili olmadıkları anlaşıldığından terk edimiştir(11, 12).

Ağrısız servikal dilatasyon ya da tekrar eden ikinci üç ay ağrısız düşük öyküsü ile kliniğe başvuran hastalarda bekleme ve izlem dışında günümüzde uygulayabildiğimiz etkili olduğuna dair veriler olan tek cerrahi tedavi yöntemi servikal serklajdır. Bu cerrahi yöntemler Shirodkar ve McDonald' in 1955 ve1957 yılında ilk tanımladıkları zamanda beri oldukça uzun bir süredir uygulanmaktadır. Her iki yöntemin birbirine üstünlüğnü gösteren veri yoktur (13).

Çalışma kapsamında servikal serklaj uygulanan toplam 56 hastanın sonuçları incelendiğinde acil serklaj uygulanan hastalara kıyasla elektif serklaj uygulanan hastaların istatistiksel olarak anlamlı olacak şekilde serklaj işlemi ile doğum arasında geçen sürenin daha uzun, gerçekleşen doğum haftasının daha ileri, doğum ağılığının daha fazla, 5. dk APGAR skorlarının daha yüksek ve yenidoğan yoğun bakım ihtiyacının daha az olduğu görülmektedir. Bizim çalışmamızda ki bu verilerden de anlaşıdığı üzere elektif serklaj uygulanan hastalar acil serklaj uygulanan hastalara göre işlemden belirgin olarak daha çok fayda görmektedirler. Yapılan bir metaanalizde gebeliğin ikinci üç ayında ağrısız servikal dilatasyonu olan hastalardan acil serklaj yapılanların serklaj yapılmayanalara göre 28 ve 32 . Hafta altı erken doğum olasılığının ve yenidoğan yoğun bakım ihtiyacının belirgin olarak daha az olduğu, gebelik süresini anlamlı olarak uzattığı ve doğum haftasının da anlamlı olarak daha ileri olduğu anlaşılmaktadır (14). Hashim ve arkadaşlarının 40 çalışmanın sonuçlarını analiz ettikleri bir derlemede, acil serklajın gebelik süresini ortalama 4-5 hafta uzattığı ve 34 haftadan önce olan preterm doğum riskini 2 kat azalttığı belirtilmiştir (15). Bizim çaIışmamızda da yapılan acil serklajlar gebelik süresini 4 haftaya

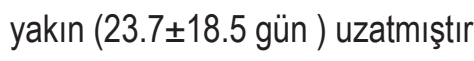

Acil serklajın servikal yetmezlik tedavisinde yararlı olduğu kabul görmekle birlikte elektif serklaja kıyasla etkinliği konusunda net bir görüş birliği yoktur. Koryoamnionit ve membran rüptürüne, acil serklaj uygulanan hastalarda daha sık rastlanılmaktadır (16). Chen ve arkadaşları tarafından yapılan bir metaanaliz, 
bizim çalışmamızın sonuçları ile uyumlu olacak şekilde elektif serklaj yapılan hastaların doğumun gerçekleştiği gebelik haftasının daha ileri, bebeklerin doğum ağırığının da daha fazla olduğunu ortaya koymuştur (17).

Elektif ve acil serklaj yapılan hastaların dahil edildiği bir çalışmada ortalama doğum haftası sırasıyla $36.1 \pm 3$ ve $35.6 \pm 3$ hafta , ortalama doğum ağırlığı sırasıyla 2848 ve 2862 gr olarak bulunmuştur. İşleme bağlı komplikasyonlar açısından gruplar arasında fark bulunamamış olup, acil serklajın elektif serklaj ile karşılaştırılabilir bir etkinliğe sahip olduğu sonucuna varmışlardır (18). Benzer şekilde Wang ve arkadaşlarının yaptığı başka bir çalışmada da acil ve elektif serklaj karşılaştııııış olup, acil serklaj yapılan hastaların ortalama gebelik süresi, doğum ağırığı, Apgar skoru gibi gebelik sonuçları açısından elektif serklaj kadar etkili olduğunu belirtmişlerdir (19).

Acil serklaj yapılan hastalarda membran prolapsusu olması ya da servikal açıkığın $1.5 \mathrm{~cm}$ üzerinde olması servikal serklaj başarısızlığı ile ilişkili bağımsız bir risk faktörü olduğu gösterilmiştir (15). Bizim çalışmamızda acil serklaj uygulanan hastalarımızın çoğu (21 hastanın 12'si) kötü prognoz beklentisi fazla olan servikal açıklık ile başvuran ve poşu prolabe olan hastalardı. Bu durumun çalışma grubumuzda acil serklajın etkinliğinin elektif serklaja kıyasla belirgin olarak daha az olmasının nedeni olduğunu düşünüyoruz.

Servikal yetmezliğin gebelik süresince ilerleyen devamlı bir süreç olduğu düşünülünce acil serklajin elektif serklajdan daha az etkili olması beklenen bir sonuçtur. Acil ve elektif serklajın benzer etkinliğe sahip olduğunu gösteren çalışmaların olması hasta seçimi ile ilişkili olması muhtemeldir. Literatür incelendiğinde serklaj endikasyonunun tanımlamalarııın oldukça değişken olduğu, standart bir tanımlamanın olmadığı görülmektedir. Bazı çalışmalarda acil serklaj grubuna sadece fizik muayenede servikal açıklığı olan hastalar alınmaktayken bazılarında ise bu hastalara ek olarak ultrasonografide kısa servikse sahip ve ağırısız preterm doğum ve/veya ağrısız ikinci üç ay abortu olanlar dahil edilmektedir. Servikal açıkığı olanların prognozu en kötü olduğundan grup içindeki ağırlıklarına göre sonuçları da etkilemektedir.

Subklinik intraamniotik enfeksiyon ya da enflamasyonun serklaj başarısını etkileyen bir faktör olduğu hatta servikal mekanik olaylar kadar önemli olduğu yönünde görüşler de mevcuttur (20). Subklinik korioamnioniti dışlamak amacıyla amniosentez yapıImasının başarıyı artırabileceği düşünülmüş ancak Mönckeberg ve arkadaşlarının çalışmasında amniosentez ile subklinik enfeksyon ya da enflamasyonun dışlanmasının acil serklaj başarısını arttırmadığı gösterilmiştir. Son yapılan metaanaliz de amniosentez yapılıp yapılmamasından bağımsız olarak acil serklajın etkili olduğu yönündedir $(14,21)$.

Acil ya da elektif serklajın doğum şekli üzerine (vajinal ya da sezeryan doğum) her hangi bir etkisi olmadığı yönünde genel bir görüş birliği mevcuttur. Bizim çalışmamızın sonuçları da aynı yöndedir $(17,19)$.

Retrospektif bir çalışma olması, hastaların bir kısmının işlem sonrası takip ve doğumlarının başka merkezlerde olmasından dolayı hasta sayısının azıı̆ı çalışmamızın zayıf yönleridir. Hasta gruplandırmasının kabul görmüş tanımlamalara uygun olarak yapılması ve değerlendirmelerin buna göre yapılması nedeniyle sonuçlarımızın literature katkısı olacağını düşünüyoruz.

\section{SONUÇ}

Ağrısız servikal açıklık ile başvuran ya da ultrasonografide belirgin kısa servikse sahip hastalarda yapılan acil serklaj ile her ne kadar gebelik süresi uzatılııp kötü perinatal sonuçlar azaltılsa bile acil serklaj gebelik süresini uzatmakta elektif serklaj kadar etkili değildir. Elektif serklaja kıyasla acil serklaj etkinliğini belirlemek için acil serklaj uygulanan hastaların daha iyi randomize edildiği daha fazla hasta sayısı ile yapılacak prospektif çalışmalara intiyaç vardır.

\section{KAYNAKLAR}

1. Stupin JH, David M, Siedentopf J-P, Dudenhausen JW. Emergency cerclage versus bed rest for amniotic sac prolapse before 27 gestational weeks: a retrospective, comparative study of 161 women. European Journal of Obstetrics \& Gynecology and Reproductive Biology. 2008;139(1):32-7.

2. McNamee KM, Dawood F, Farquharson RG. Mid-trimester pregnancy loss. Obstetrics and Gynecology Clinics. 2014;41(1):87-102.

3. Obstetricians ACo, Gynecologists. ACOG Practice Bulletin No. 142: Cerclage for the management of cervical insufficiency. Obstetrics and gynecology. 2014;123(2 Pt 1):372-9.

4. Vyas NA, Vink JS, Ghidini A, Pezzullo JC, Korker V, Landy $\mathrm{HJ}$, et al. Risk factors for cervical insufficiency after term delivery. American journal of obstetrics and gynecology. 2006;195(3):78791.

5. Iwahashi M, Muragaki Y, Ooshima A, Umesaki N. Decreased type I collagen expression in human uterine cervix during pregnancy. The Journal of Clinical Endocrinology \& Metabolism. 2003;88(5):2231-5.

6. Final report of the Medical Research Council/Royal College of Obstetricians and Gynaecologists multicentre ran- 
domised trial of cervical cerclage. MRC/RCOG Working Party on Cervical Cerclage. British journal of obstetrics and gynaecology. 1993;100(6):516-23.

7. Berghella V, Keeler SM, To MS, Althuisius SM, Rust OA. Effectiveness of cerclage according to severity of cervical length shortening: a meta-analysis. Ultrasound in obstetrics \& gynecology : the official journal of the International Society of Ultrasound in Obstetrics and Gynecology. 2010;35(4):468-73.

8. Berghella V, Odibo AO, To MS, Rust OA, Althuisius SM. Cerclage for short cervix on ultrasonography: meta-analysis of trials using individual patient-level data. Obstetrics and gynecology. 2005;106(1):181-9.

9. Ehsanipoor RM, Seligman NS, Saccone G, Szymanski LM, Wissinger $C$, Werner EF, et al. Physical Examination-Indicated Cerclage: A Systematic Review and Meta-analysis. Obstetrics and gynecology. 2015;126(1):125-35.

10. Paton MC, McDonald CA, Allison BJ, Fahey MC, Jenkin G, Miller SL. Perinatal brain injury as a consequence of preterm birth and intrauterine inflammation: designing targeted stem cell therapies. Frontiers in neuroscience. 2017;11:200.

11. Sciscione AC. Maternal activity restriction and the prevention of preterm birth. American journal of obstetrics and gynecology. 2010;202(3):232. e1-. e5.

12. Grobman WA, Gilbert SA, lams JD, Spong CY, Saade G, Mercer BM, et al. Activity restriction among women with a short cervix. Obstetrics and gynecology. 2013;121(6):1181.

13. Berghella V, Rafael TJ, Szychowski JM, Rust OA, Owen J. Cerclage for short cervix on ultrasonography in women with singleton gestations and previous preterm birth: a meta-analysis. Obstetrics \& Gynecology. 2011;117(3):663-71.

14. Chatzakis C, Efthymiou A, Sotiriadis A, Makrydimas G. Emergency cerclage in singleton pregnancies with painless cervical dilatation: A metalanalysis. Acta Obstetricia et Gynecologica Scandinavica. 2020;99(11):1444-57.
15. Hashim HA, Al-Inany H, Kilani Z. A review of the contemporary evidence on rescue cervical cerclage. International Journal of Gynecology \& Obstetrics. 2014;124(3):198-203.

16. Harger $\mathrm{JH}$. Cerclage and cervical insufficiency: an evidence-based analysis. Obstetrics and gynecology. 2002;100(6):1313-27.

17. Chen $Q$, Chen G, Li N. Clinical effect of emergency cervical cerclage and elective cervical cerclage on pregnancy outcome in the cervical-incompetent pregnant women. Archives of gynecology and obstetrics. 2018;297(2):401-7.

18. Gluck O, Mizrachi Y, Ginath S, Bar J, Sagiv R. Obstetrical outcomes of emergency compared with elective cervical cerclage. The Journal of Maternal-Fetal \& Neonatal Medicine. 2017;30(14):1650-4.

19. Wang S, Feng L. A single`center retrospective study of pregnancy outcomes after emergency cerclage for cervical insufficiency. International Journal of Gynecology \& Obstetrics. 2017;139(1):9-13.

20. Oh KJ, Romero R, Park JY, Lee J, Conde-Agudelo A, Hong $\mathrm{J}-\mathrm{S}$, et al. Evidence that antibiotic administration is effective in the treatment of a subset of patients with intra-amniotic infection/inflammation presenting with cervical insufficiency. American journal of obstetrics and gynecology. 2019;221(2):140. e1e18.

21. Mönckeberg M, Valdés R, Kusanovic JP, Schepeler M, Nien JK, Pertossi E, et al. Patients with acute cervical insufficiency without intra-amniotic infection/inflammation treated with cerclage have a good prognosis. Journal of perinatal medicine. 2019;47(5):500-9. 